\title{
FLOWS - A Design-based Process Model for Value Innovation from solid waste
}

\author{
Cláudio Pereira de Sampaio ${ }^{1 a}$, Suzana Barreto Martins ${ }^{2}$, Fernando Moreira da Silva ${ }^{3}$, Rita Assoreira Almendra ${ }^{4}$ \\ ${ }^{1,2}$ Londrina State University - UEL, Design Department, Londrina-Brazil \\ ${ }^{3,4}$ Lisbon University, Faculty of Architecture - FA.ULisboa, CIAUD, Lisbon-Portugal
}

\begin{abstract}
This paper proposes a model of $R \& D$ process for facing the problem of solid waste, supported by an interdisciplinary approach oriented by design thinking, design for sustainability and business models design. The aim of this model is to help the innovation teams, and especially the $R \& D$ teams in developing their projects about solid waste solutions. For better understanding the problem, the authors carried out this study in five parts: 1) critical literature review and semi-structured interviews with specialists; 2) an exploratory study by active research with a group of Brazilian design students/researchers; 2) the design of the methodological model for the R\&D process; 3) the test of the model with a quasi-experiment with two sample and two control groups formed by other Brazilian design students, and 4) complementary tests with other 12 groups from three different universities, being two of Brazil and one of Portugal. The results indicated that the model can be useful for helping creative groups to develop value solutions from the problem of the solid waste, and especially the utility of the Value Proposition Canvas and Business Model Canvas tools for designing value propositions. The study also pointed out the relevance of the stage of customer/user research, especially the direct methods and tools for collecting and analyzing data. Finally, the study highlights the importance of the prototyping stage, including an adequate structure and resources for this activity, and the utility of both the product prototypes and the Minimum Viable Product (MVP) prototypes.
\end{abstract}

Keywords. Solid waste, value innovation, design thinking, design for sustainability, business models, creative teams.

\section{Purpose}

The end of life of textile waste is a significant and growing problem in Brazil and many other countries, and especially in those where textile and garment industry sectors are economically relevant. Environmental, social and economic problems caused by inadequate disposal of this waste include loss of life quality, land, water, and air (when burning) pollution and contamination, and extra costs with destination for companies and public authority, among other consequences.

The relevance of this problem was the starting point for the study described in this paper and influenced by the previous experience acquired by two of the authors in several research projects in this subject, with other types of materials (marble \& granite, corrugated cardboard, plastics, wood, steel, stone, sand). In fact, this last aspect was determinant for the chosen methodology for starting this study, based on active research and quasiexperiment, because they allowed working with existing $\mathrm{R} \& \mathrm{D}$ groups led by the authors.

On the other hand, that previous R\&D experiences allowed authors to verify the lack of a clear process that the researchers could follow when trying to understand the problem of solid waste and then design, test and implement environmentally sustainable, economically valuable, socially acceptable and technically feasible solutions.

These various requirements were determinant for the proposal of developing a model of $R \& D$ process that could allow developing solutions for the waste, by creating new materials, products, and even new business models seemed to be an interesting and promising approach. So, design (and especially design thinking) was an evident option to guide the R\&D process model, due to its characteristics of empathy to better understand the market and user needs, and the experimentation (ideation and test) of new ideas. Similarly, Design for Sustainability (DfS) was chosen as an appropriate way to consider the sustainability issues in the R\&D process. But when developing new materials knowledge of other disciplines beyond design are needed, as chemistry and materials engineering, to deal with specific aspects of the matter. Green Chemistry and Green Engineering fields were chosen to allow include these requirements and integrated with the DfS, in the form of principles and guidelines.

This study is part of a doctorate thesis developed by one of the authors, in which an integrated model for R\&D management (FLOWS Model) was built. This model is

\footnotetext{
${ }^{\mathrm{a}}$ Corresponding author: qddesign@ $\mathrm{hotmail.com}$
} 
formed of five distinct parts - project planning, team management, leadership, process management and final products. This complete integrated model (FLOWS) were previously presented in another paper (SAMPAIO et al, 2016), and the development of some of its parts in six other papers: the process (SAMPAIO et al, 2015a; 2016a; 2016c; 2016d) and the team and leader (SAMPAIO et al, 2015b; 2016b).

In this paper, only the process management will be explored, focusing on the following stages of its development: the active research with research groups of the authors, the design of an R\&D process model detailing its steps, activities, methods and tools, and the evaluation carried out by quasi-experiment with sample and control groups and in addition to a dozen of other complementary groups.

\subsection{Problem and hypotheses/assumptions}

The context of this interdisciplinary project, in which design and chemistry researchers joined efforts, was enough explored in other papers (MARTINS et al, 2014), and here we underline some relevant achievements and learnings that guided the development of the FLOWS model:

-The inefficacy of the solutions presently adopted by the industries (sending to landfills, collect by non-certified companies or individuals, donation for artisans, incineration);

-The high tax of waste of materials that could be of economic value, between $20-30 \%$;

-The need of both preventive (e.g. zero waste) and corrective approaches (e.g. FLOWS model);

-The development of new materials from the waste as a promising possibility in terms of new added-value products and business, with reflections in new jobs, incomes, and the local economy;

-The need for an interdisciplinary approach to face the problem of waste, as well as the development of new materials, products and businesses;

-The potential of design in terms of its logic of reasoning to solve problems and explore opportunities (design thinking and design process), that could guide this value-based innovation process;

-The potential of design simultaneously acting in three levels as an R\&D strategy planner (strategic), project planner (tactical) and activities or tasks (operational);

These findings served as the starting point to establish some preliminary hypotheses that, for instance, guided the development of the FLOWS model:

- The development of new materials from the solid waste can be a viable and valuable solution for this problem, and can be better conducted by using a systematic and methodologic structured $\mathrm{R} \& \mathrm{D}$ process; in addition, these new materials can be used to develop new products and even new business models, and these activities also can be integrated into the R\&D process;

-Interdisciplinary is a necessary condition for this type of $R \& D$ project because its complexity requires a lot of different competencies that is not owned by only one knowledge area. Design can take the role of manager for this integrated R\&D process, due to its characteristics of integrative and strategical thinking and envision, empathy and applied creativity.

\subsection{Proposed approach}

The design was chosen as the main element to orient the development of the FLOWS model because of its specific type of reasoning to face complex problems, or what Dorst calls « ill-defined problems » (DORST, 2009): the abductive reasoning. Abduction differs from other types of reasoning as induction or induction because it allows the researcher to include the imaginative (abductive) thinking in the process.

Also, Dorst proposed that different from the inductive or deductive way in that the desired result is one right and observable answer, the abductive process aims to find a value, that is, the most suitable answer for a specific context. So, value (a set of benefits) is the final product aimed in the "equation » of design, in which the «What» represents the object to be developed (material, product, service, business model) and «How» the working principle behind it (process, method, structure).

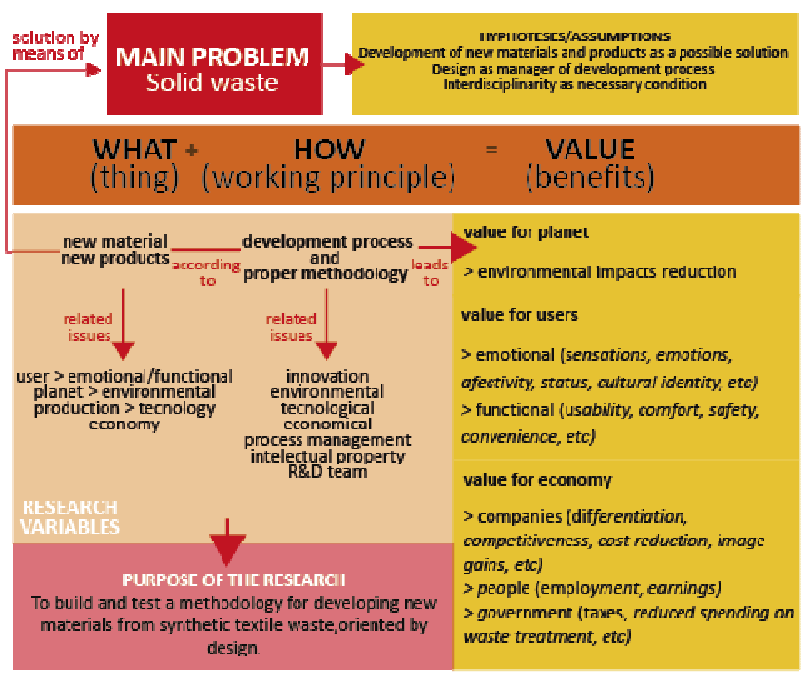

Figure 1. The abductive reasoning applied to the study and the elements of FLOWS model (traced rectangle).

In this study, the «design equation» served as the foundation for structuring and identifying the issues that should be studied, as well as the elements that should be present in the FLOWS model, as the «How » of the equation, in Figure 1 (SAMPAIO et al, 2014).

\subsection{Theoretical foundations}

The underlying approach for the FLOWS model was based on design and four of its specific areas of study: 
design thinking (including design processes, methods, and tools), design for sustainability (DfS), materials design and business models design. These areas influenced both the proposed R\&D process and the other elements of the model. The theoretical foundations for the FLOWS model, including the team and leader aspects, were well detailed in several other papers (SAMPAIO et al, 2015a; 2016a; 2016c; 2016d; 2015b; 2016b). In short, these theoretical and practical approaches can be thus explained:

-Design thinking: Lockwood (2006) define this approach as a humanistic and creative way to solve complex problems and explore opportunities, considering people as the starting point for the innovation process, so empathy for them and design and experimentation of new ideas are its the core elements.

- Design for sustainability (DfS): Aims to include social, environmental and economic guidelines and requirements in the whole process of developing and implementing goods and services for people. For the environmental aspect, considers the entire life cycle of products and services, and its related strategies for reducing impacts (life cycle design).

- Green Chemistry: According to Anastas et al $(1998,2000)$ is the development of chemical products and processes that reduce or eliminates the use and generation of hazardous substances in the development, production, and application of chemistry. It is operationalized by twelve principles, to prevent waste and accidents, avoid or minimize toxicity, use energy efficiently and use renewable resources.

- Green Engineering: Anastas e Zimmerman (2003) define this approach as the development and selling of industrial processes that be economically viable and reduce risks to human health and the environment. Similarly to the previous approach, is guided by eleven principles, and is strictly related to the concept of Cleaner Production.

- Materials design: The development of new materials was seen as a key macro trend for the future of design field, according to MDIC (2014). In fact, this activity was pointed out since the 90's as one of the new promising activities for the designers by Manzini (1993).

-Business models design: The increasing of the importance of design for the business in the recent decades as a value creating tool have resulted in the emergence of a new generation of methodologies, methods, and tools for innovation, mostly focused on creativity and simplicity of use, by adopting visuality as a new form of communication and ideas exchange. Lean innovation concepts like lean startup (RIES, 2010) have become the new standard, to achieve agility and effectivity in the innovation process. The concept of Minimum Viable Product (MVP) is a fundamental element in this approach and it refers, in short, as a product (or service) with a minimum set of relevant features that can be tested with users in the real world. In addition, tools like Business Model Canvas and Value Proposition Canvas (OSTERWALDER, PIGNEUR, 2011; OSTERWALDER et al 2014). have gained prominence due to the easiness, effectivity, and efficiency of use.

All these approaches together compound the foundation of the R\&D process model next presented and discussed in this paper.

\section{Methods}

The methods used to operationalize this research can be divided into four parts:

- Part 1, carried out with an R\&D group led by two of the authors, dedicated to understand the problem and build up the state of the art in the issues related to the study, included critical literature review and semi-structured interviews with R\&D specialists;

- Part 2, also with this R\&D group, was conducted in the form of an active research and aimed to learn from the challenge put to the group, which consisted of developing new solutions for the problem of a specific type of waste (textile polyamide 6.6 from garment);

- Part 3, included the development and detailing of the methodological model for the R\&D process, including its steps, methods, and tools;

- Part 4, dedicated to testing the proposed model and analyze the results to verify its validity, by means of active research, quasi-experiment and additional tests with other groups.

Next, the activities of parts 2, 3 and 4 will be presented in detail. More specifically, in the evaluation carried out with the groups in the Part 4 , the aim was to verify the validity of part of the R\&D process model based on the use of some fundamental methods and tools for value innovation: Value Proposition Canvas, Business Model Canvas, product prototypes and Minimum Viable Product (MVP) prototypes (OSTERWALDER, PIGNEUR, 2011; OSTERWALDER et al 2014).

\subsection{Active research}

This interventionist method of active research was applied by the main author with his R\&D group in the Design Department of Londrina State University during the years of 2013-2014. This project involved 16 students, being 12 of Bachelor in Fashion Design, 02 of Bachelor in Graphic Design and 02 of Chemistry (01 Bachelor and 01 Master student). They were coordinated by 03 professors, being 02 of Design and 01 of Chemistry.

The group was divided into 08 teams, each one with specific attributions in the process. In addition, 03 partnerships for the project were established: a garment 
industry that donated PA66 textile waste for the experiments, a plastic injection and extrusion company that made viable the tests with new materials obtained in the R\&D process, and the Innovation Agency of the UEL University, that allowed training in new business models for 06 students of the team.

The results obtained by the researchers in this project were significant, and included: 03 different methods of extracting PA66 from the textile waste and one of melting it to produce new objects; a product line compound of 06 products for interior lightning, a bowl and a board, using the melting process; and 02 business models considering the PA66 waste and the innovations as the key resource to new value propositions. The project also included a test of acceptation with the audience, by using a dedicated website and participating in an innovation fair.

This active research was fundamental to design, test and refine the first version of the R\&D process model (so called "protomodel of the process"), that was conceived based on the critical literature review, as well as on the previous experience of the author as a researcher in this type of project.

\subsection{The R\&D Process Model}

The final version of the R\&D process model is presented in Figure 2. It is structured in nine distinct stages, organized in two specific moments: the first one is dedicated to understanding the problem of a specific solid waste (1-Problem Context) and to do experiments with the waste to obtain a «protomaterial» (2-Waste Experiments). This moment is mainly guided by principles and guidelines coming from life cycle design, green chemistry, and green engineering, as well as applied creativity to explore material possibilities.

The second moment of the process is inspired both by the approach of design thinking, process, methods and tools, and the business models, aiming to create and deliver value for users/customers, economy, and environment. This moment includes 07 subparts/stages: 3a-Technology Description, 3b-Value Proposition Draft,
4-Market Segment, 5-Customer Segment, 6-Minimum Viable Product (MVP) \& Business Model, 7-Material Evolution, and 8-Impementation.

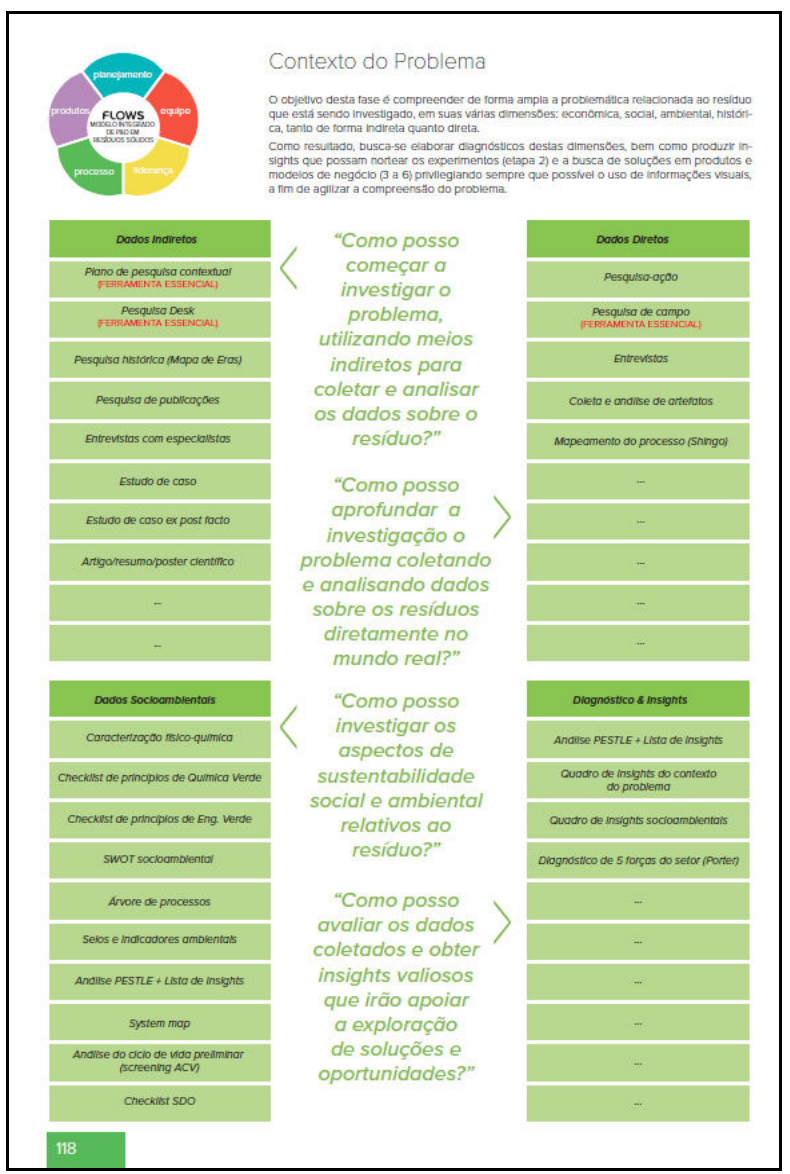

Figure 3: Example of worksheet for a tool used in the phase of Problem Context.

Each stage contains a set of tools (Example in Figure 3) that allows to operationalise the R\&D process, and facilitates the choice of the tool depending on the level of knowledge and skills fo the team, the amount of time available for the project, or other variables that can be considered by the R\&D project leader. Each tool has its own worksheet (Figure 4), which contains a synthetic

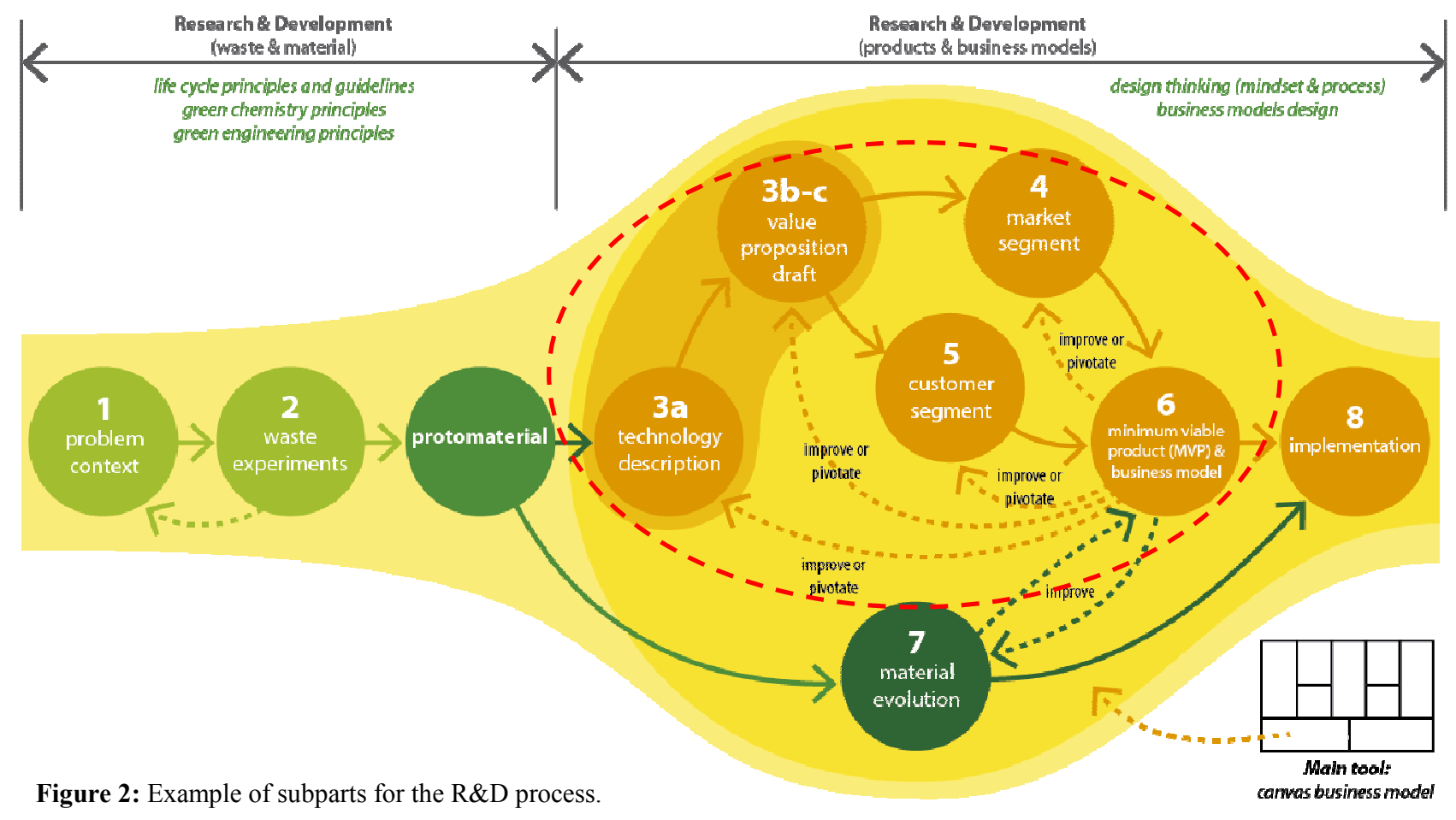


description of the tool, its utility, when and how to use it, the inputs and outputs involved, and some references for additional research.

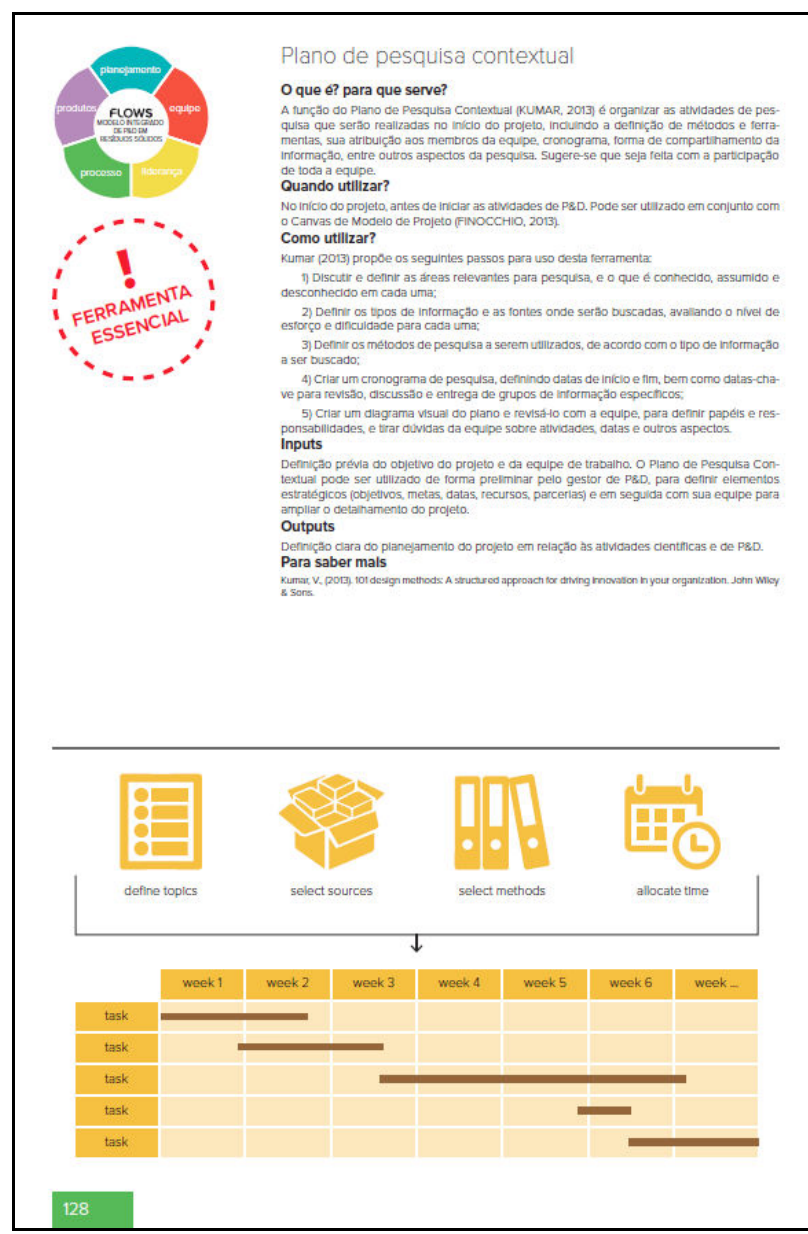

Figure 4: Example of the worksheet for a tool used in the phase of Problem Context.

Because of the focus on developing value propositions in this moment of the process, there is a main convergent tool that is used along with these 7 stages: The Canvas Business Model (OSTERWALDER, 2011), that is a graphic and textual representation of a business model and its main parts. An example of this tool filled by one of the evaluation groups can be seen in Figure 9.

For the quasi-experiment, and due to time and resources restrictions, the author chose for testing with the groups only the stages 3a, 3b, 4, 5 and 6 (Figure 2, dashed circle) of the R\&D process model, that is, the stages aimed at creating value innovation from a technological innovation (the « protomaterial ») previously developed.

\subsection{Quasi-experiment and additional evaluations}

The evaluation of the model for R\&D process was made in two distinct parts: first, the quasi-experiment method was applied to 02 sample and 02 control groups of 04 students each, during six weeks; second, with other 12 groups, being 02 groups during one week, 08 groups during 06 weeks and 02 groups during 16 weeks. Overall, 52 Design students (48 female and 04 male) from 03 universities (02 form Brazil and 01 from Portugal) participated in the evaluation.

For the sample and control groups, the independent variable was defined in the form of a strictly defined project challenge in which they should develop, prototype and test among users a value proposition based on a "protomaterial" just developed by the author research team in the phase of active research. One relevant restriction is that the value proposition should include a user-testable product (Minimum Viable Product, or MVP), a value proposition (using the Value Proposition Canvas tool, e.g. Figure 8) and its related business model (using the Business Model Canvas tool, e.g. Figure 9).

For the sample groups, the tools to be used in the project were previously defined, while the control groups were free to define their own tools. Besides this, que sample and control groups had the same time for the project: six weeks.

The dependent variables to be observed in the quasiexperiment were the quality of the solutions provided by the groups, in terms of adequacy to the users (defined by each team), innovative approach to the problem and viability of the proposal. In other words, what was evaluated is how using (or not) that proposed part of FLOWS process model could influence the results obtained by the groups.

\subsection{The "protomaterial" as the starting point}

All the groups received the same technological innovation (a "protomaterial", in Figure 5) from what they should develop a value innovation: a process of reusing synthetic textile waste of PA66 by melting it at $260^{\circ} \mathrm{C}$ and then conforming it by open-moulding. This innovation was developed by the R\&D team of the authors, as just commented.

In the context of the use of Business Model Canvas, this "protomaterial" corresponds to start designing a business model from the "Key Resources". In fact, is very frequent, according to Osterwalder (2011), to start an innovative value proposition and business model from some type of technological innovation already available or developed by the R\&D team, company or another partner. This case is particularly suitable for the $R \& D$ process model here proposed. 


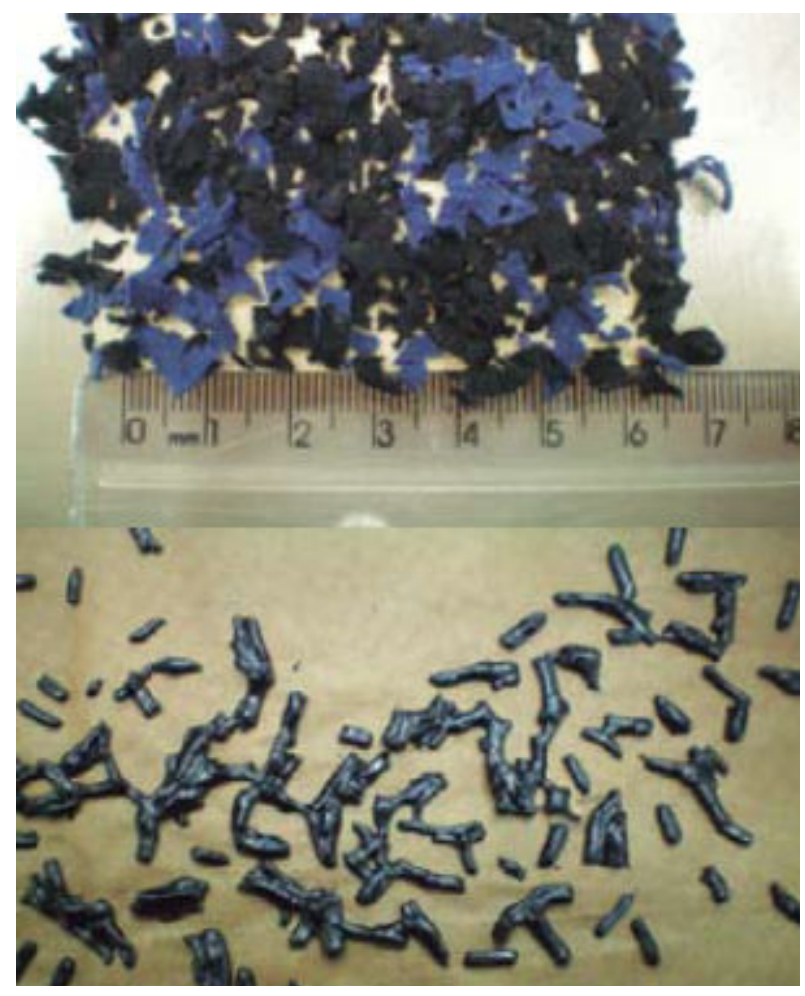

Figure 5: The "protomaterial" obtained by melting PA66 textile waste using heat.

\section{Results from the group's evaluation}

\subsection{Evaluation by quasi-experiment with sample and control groups}

Both sample and control groups met the proposed challenge of developing a value proposition and product (Figure 6, 7), but using distinct project approaches.
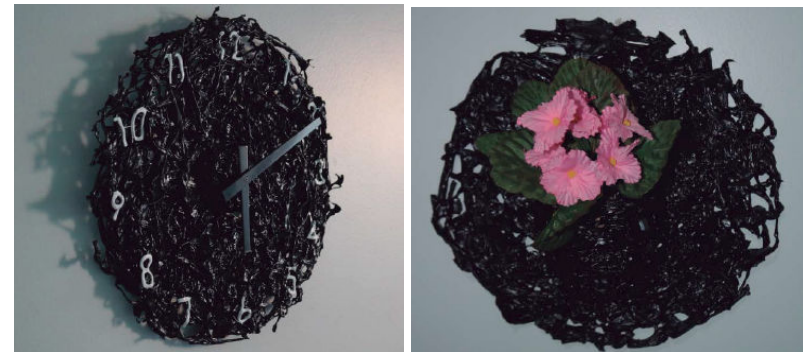

Figure 6: Prototypes made by the two sample groups, using the "protomaterial".
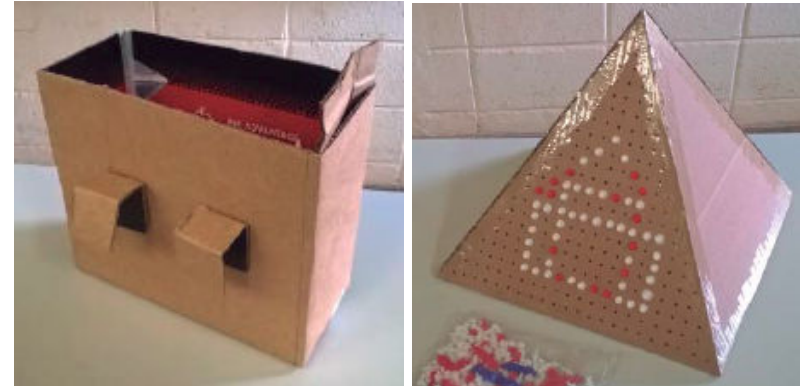

Figure 7: Mockups made by the two control groups.
The results of these groups can thus be summarized:

- All groups had a good understanding of the starting point technology (the «protomaterial») by manipulating material samples and reading papers and other documents about it;

- None of the groups carried out direct research with the customers/users but, instead, all of them chose to use indirect methods, like desk research, persona, micro and macrotrends, and so on;

- All groups used indirect methods of collecting data of market segment, but the sample groups did this activity this more in-depth, specially for similar products and brands;

- All the groups understood and were able to use the Value Proposition Canvas satisfactorily (example in Figure 8), but one of the sample groups made a richer and more complete canvas, due to a good market data collection;

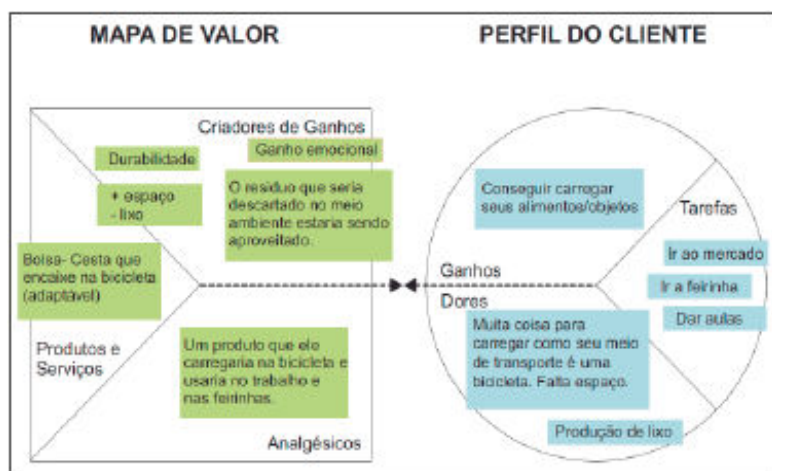

Figure 8: Value Proposition Canvas made by one of the control groups.

- Although the control groups used the Value Proposition Canvas correctly, they found difficulties in defining a good set of user tasks, pains and gains, as well as the value proposition and, consequently, the final product;

- All the groups had difficulties in differentiating user gains and pains from gain creators and pain relievers;

- One of the control groups found it difficult to understand how to use Value Proposition Canvas when customer and user are not the same. It is recommended to use one canvas for each, what was not done by this group;

- Business Model Canvas was used only by the control groups (example in Figure 9), while the sample groups concentrated their efforts in defining more rigorously the Value Proposition Canvas. Thus, the sample groups didn't detailed enough the other business aspects, like business partners, channels, or financial issues, but they built a deeper vision of the customer/user segment;

- For the control groups, the most difficult aspects of the business model to be defined was the cost structure needed to make viable the key activities for the business. The students justified this fact by argumenting that this aspect is not enough addressed in the graduation course; 
- Besides this, the control groups produced good ideas to diversify the revenue streams beyond only selling the product. The students stated that a greater emphasis on systemic thinking in the graduation course could help them to develop the ability to conceive a business model in a more enlarged and integrated way;

- Both sample and control groups elaborated good drawings and mockups to represent their ideas among the team members and for the project coordinator. However, the sample groups produced prototypes using the proper «protomaterial» and, thus, could better learn and explore about technical and aesthetical issues related to the product;

- The sample groups made their prototypes off the university space, due to the lack of appropriate structure and equipment;

- Beyond the product prototype, the sample groups also produced Minimum Viable Product (MVP) prototypes like landing page and promotional video, with the aim of testing the acceptance with users, while the control groups only produced mockups that are useful to represent the volume of the product, but not other aesthetical and functional aspects;

- None of the groups tested the value propositions, business model and product prototype with users, and all of them justified this because of the lack of adequate time.

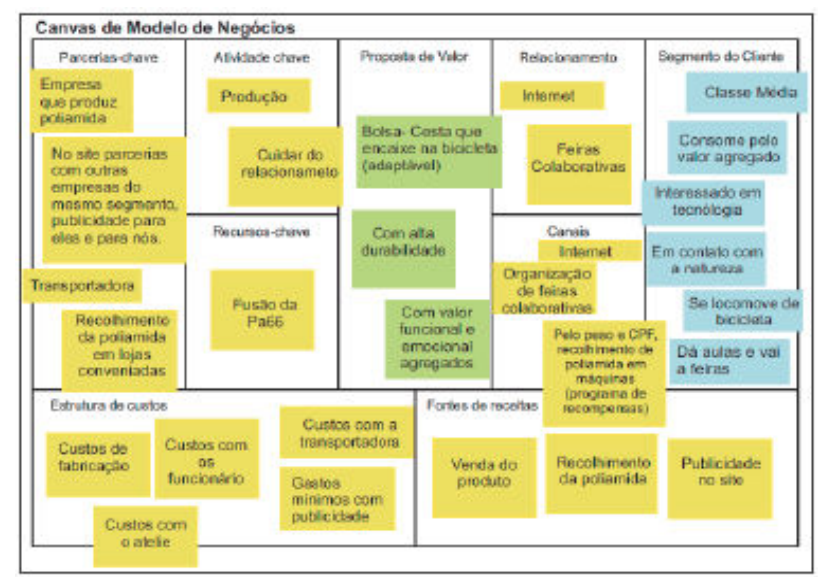

Figure 9: Business Model Canvas made by one of the control groups.

In short, while the sample groups dedicated their efforts to understand the customer/user and market and to the prototyping and preparing the test of the value propositions with them, the control groups chose to draw the business model as a whole. Thus, it can be inferred that, if an additional project time would be provided for the groups, the challenges would be very distinct: the sample groups should detail the other business aspects and test the MVP prototypes with the users, while the control groups should prepare the PVM prototypes and test it with the users.

In terms of complexity, it can be assumed that the sample groups would have an advantage over the sample groups, because of two reasons: 1) the greater understanding of the customer/user and market by the sample groups led them to develop a better value proposition ; 2) due to the higher quality of the value propositions, the MVP prototypes could be better developed considering the attitudinal and behavioural aspects of the users ; 3) in general, designing the other aspects of the Business Model Canvas can be seen as less complex than preparing the MVP prototypes. A preliminary version of the first can be carried out in one or two group meetings, while the second requires much more time.

It must be underlined that none of the groups dedicated enough time to direct research with customers/users, although the sample groups have made a better indirect data collection and analysis. A most immersive and ethnographical approach is essential to understand who is the real public in a project, and the project coordinator must provide adequate methods and tools for this to its R\&D team.

The role of prototyping in the process proved to be fundamental in the process, as well as the need of a minimum adequate infrastructure and resources for it. Thus, these elements cannot be underestimated by the R\&D manager when planning a project, because it can make the project unfeasible.

\subsection{Evaluation by testing with the complementary groups}

Beyond the quasi-experiment, a complementary test was carried out with other 12 groups from 03 different universities. Some results were like the quasi-experiment group, and other were distinct, as it follows:

- A good understanding of the proposed technology (the "protomaterial") was common for all the groups;

- The 16-week project groups managed their time very differently. One group knew how to well balance the stages of user definition and research, ideas generation, and prototyping, but the other faced problems in organizing its work and time. Thus, the quality of design proposals of the first group was evidently better;

- This group, interestingly, is only of the 12 groups that used direct data collection (interviews, field visit in shops) about the customer/user and market. All the other groups used indirect research (desk research, similar products, and brands, persona) about customers/users, what resulted in a more superficial definition of them; in fact, 05 groups did not even perform this stage;

- In the same way, this group was the only that built PVM prototypes for testing the acceptance of the value proposition with the customers/users;

- Of the 12 groups, 07 successfully understood and used the Value Proposition Canvas, and 02 didn't perform this activity, preferring to use the Business Model Canvas because of the short time, as they themselves stated;

- The confusion between pains and gains, and pain relievers and gain creators were also common for all the 12 testing groups; 
- The groups that didn't perform good customer/user and market research also faced difficulties in design good value propositions;

- The drawing was chosen as the most common resource for representing the ideas, what was a problem for 04 groups, that presented them with a poor quality, that made difficult to understand the proposal;

- 04 of the 12 groups produced mockups to preliminary test of the ideas, and none of the 06-week groups performed this activity;

- None of the groups tested the proposal with the segment of customer/user, either of interaction between user and product prototype or the acceptance of the value proposition by using PVM prototypes;

- Business Model Canvas was used by 10 of 12 groups, and 02 failed to use it due to an inadequate time management. The quality of the canvas produced by 7 groups was considered acceptable by the project coordinator, and 03 non-acceptable due to inaccuracies or lack of information;

- The most frequent difficulties in using Business Model Canvas were, according to the students, related to the difference between relationship and channels, and key activities and resources, as well as in defining the financial aspects (cost structure and revenue streams);

- The ability to give creative answers was observed in all the groups, but not even well supported by a good research. That is, the most challenge was not in the phase of generating and testing ideas, but in the phase of collecting and analyzing enough data and correctly defining the customer/user. In fact, only a group fulfilled this task in an acceptable manner;

- Of the 07 groups that worked during 06 weeks, 04 obtained a satisfactory result in terms of product, value proposition and business model, and none of them performed the data collection and analysis satisfactorily;

- Surprisingly, the results of the one-week groups could be considered approximately in the same level of quality of the 06-week groups, although they also been superficial in terms of the understanding and definition of the customer/user. In addition, the one-week groups dedicated more time and effort experimenting with the "protomaterial", due to the availability of prototyping infrastructure. Thus, it can be affirmed that, if the 6week groups would decide to produce prototypes instead of only mockups this would be possible for them if they organized their time better. But is relevant to say that these last groups also found difficulties in using an adequate infrastructure for prototyping in their university;

- In the case of 16-week groups, in can be affirmed that this time is enough to carry out a first complete cycle of R\&D, from a "protomaterial" to a proposal of value proposition and business model. It was noted that in 6 weeks is already possible to obtain good preliminary results, and with more 2 or 3 weeks is possible to perform a consistent collection and analysis data, including a field research with users, and a week for testing the proposals with them;
- Therefore, it was proposed that around 9 weeks can be enough for a complete cycle of R\&D from a "protomaterial" previously defined.

\section{Findings}

In short, it was observed in almost all the groups a lack of attention and effort in the stage of research, and especially that related to the customer/users, essential for a deeper understanding of their needs and desires. Part of this problem is related to a poor management of the time in the project, but also due to a poor comprehension about the real importance of this stage in the $R \& D$ process.

Besides that, it was noted a lack of attention to the stage of prototyping, in part due to the absence of an adequate infrastructure, but which could be minimized by better exploring the use of mockups or models.

Therefore, although the groups have been showed a good level of creativity to develop ideas, the difficulties mentioned above were decisive for compromising, in many of the groups, the final quality of their projects in terms of adequacy and feasibility.

One of the most remarkable aspects noted in the evaluations were the easiness and fastness in learning how to use the methods and tools by the groups. The attribute of visuality and simplicity can be seen as an essential aspect that influenced this fact.

\section{Conclusions}

The initial aim of validating part of the R\&D process model with groups can be considered achieved, because it was possible to test the use of the proposed methods and tools, like Value Proposition Canvas, Business Model Canvas, product prototypes and Minimum Viable Product (MVP) prototypes. The strategy of quasiexperiment can be considered appropriated and useful for this study, as well as the complementary test with other groups because they resulted in a very rich set of qualitative data that could be exhaustively compared and analyzed.

On the other hand, it is also relevant to note that the method of active research played a fundamental role in the phase of developing the R\&D process model, and resulted in a process model that was built not only based on the literature, but also in the practice of the research group coordinated by the author.

The next steps of this study include additional applications of the R\&D process model with other R\&D groups, what is even being now with 03 new groups coordinated by the author. The aims are to refine the model, eventually including or suppressing some tools, and especially verifying the utility of the stages and sets of tools that were not tested with the groups described in this paper. 


\section{Acknowledgments}

The authors thanks to $\mathrm{CNPq}$ for the financial support that made possible this study, and the partner universities and their professors and students that collaborated with the main author to carry out the study.

\section{References}

ANASTAS, P. T., WARNER, J. C. Green Chemistry: Theory and Practice, Oxford University Press: New York, 1998, p.30. By permission of Oxford University Press. Available

at: http://www.acs.org/content/acs/en/greenchemistry/about/ principles/12-principles-of-green-chemis-try.html.

[Accessed dec 13 2013].

ANASTAS, P.T., ZIMMERMAN, J.B. Design through the Twelve Principles of Green Engineering, Environmental Science and Technology, 37, 5, 94A101A. 2003. Available at: http://www.acs. org/content/acs/en/greenchemistry/about/principles/12principles-of-green-engineering.html. [Accessed dec 13 2013].

DORST, K., Design Problems and Design Paradoxes. Design Issues: Volume 22, Number 3 Summer 200622(3), pp.4-17. Available at: $<$ http://www.mitpressjournals.org/doi/pdf/10.1162/desi.2 006.22.3.4.> [Accessed dec18 2014], 2006.

HSM do Brasil, 2014.

LOCKWOOD, T. Design thinking: Integrating innovation, customer experience, and brand value. New York: Allworth Press, 2006.

MANZINI, E. A Matéria da Invenção. Coleção "Design, Tecnologia e Gestão". Centro Português de Design, 1993. Título original: La materia dell'invenzione, Milão: Arcadia, Projeto Cultura Montedison, 1986.

MDIC - MINISTÉRIO DO DESENVOLVIMENTO, INDÚSTRIA E COMÉRCIO EXTERIOR. Diagnóstico do Design Brasileiro. Documento elaborado pela Agência de Promoção de Exportações e Investimentos (Apex-Brasil) e Centro Brasil Design. Brasília, Governo Federal, 2014.

OSTERWALDER, A. PIGNEUR, Y. Business Model Generation - Inovação em modelos de negocios: um manual para visionarios, inovadores e revolucionarios. Rio de Janeiro: Alta Books, 2011.

OSTERWALDER, A., PIGNEUR, Y., BERNARDA, G., SMITH, A. Value Proposition Design. Trad. Bruno Alexander, ilustrado por Trish Papadakos. Sao Paulo:

RIES, E. The Lean Startup: How Today's Entrepreneurs Use Continuous Innovation to Create Radically Successful Businesses Crown Publishing, 2011.

SAMPAIO, C.P.; MARTINS, S.B.; ALMENDRA, R.A.; MOREIRA DA SILVA, F.J.C. New materials and products from synthetic textile waste: Development of a model for a design-oriented process development. Proceedings of the 2nd International Conference on Energy and Environment: bringing together Engineering and Economics, School of Engineering, Universidade do Minho, Guimarães, Portugal, 2015.
SAMPAIO, C.P.; MARTINS, S.B.; ALMENDRA, R.A.; MOREIRA DA SILVA, F.J.C. New materials and products from synthetic textile waste: a model for the management of the research team. Proceedings of the 5th Sustainable Development Symposium, Faculdade de Arquitetura da Universidade de Lisboa, Lisboa, Portugal, 2015.

SAMPAIO, C.P.; MARTINS, S.B.; ALMENDRA, R.A.; MOREIRA DA SILVA, F.J.C. From solid waste to value innovation: Proposal for a R\&D process based on design thınkıng, desıgn for sustainability and busıness models. In LENS/Brazil - Learning Network on Sustainability/Brazil. 1st International Symposium on Sustainable Product Service Systems and Distributed Economy. Proceedings of the $1^{\text {st }}$ SSPSS\&DE. Curitiba, Brazil: Nucleo de Design \& Sustentabilidade, Universidade Federal do Parana. Available at $<$ http://spssdeseminar.wix.com/1sspss-de $>\quad$ Accessed Aug 19, 2016.

SAMPAIO, C.P.; MARTINS, S.B.; ALMENDRA, R.A.; MOREIRA DA SILVA, F.J.C. From solid waste to value innovation: a methodological proposal for managing the team in an integrated R\&D management model. Proceedings of the Regional Helix 2016: International Conference on Regional Triple Helix Dynamics. Castelo Branco, Portugal, 2016.

SAMPAIO, C.P.; MARTINS, S.B.; ALMENDRA, R.A.; MOREIRA DA SILVA, F.J.C. Inovação e sustentabilidade a partir de residuos solidos:um modelo para o processo de I\&D. Livro de resumos do $5^{a}$ Encontro de Doutoramentos em Design, UA Editora, Universidade de Aveiro, Aveiro, Portugal. Available at

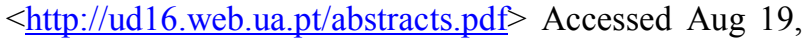
2016.

SAMPAIO, C.P.; MARTINS, S.B.; ALMENDRA, R.A.; MOREIRA DA SILVA, F.J.C. Innovation and sustainability in materials, products and business models from solid waste: a value-based model for the R\&D process. in: E. Delfino \& C. Vezzoli, eds., Proceedings of the LeNSes Conference: Sustainable Energy for All by Design, Volume X, pp 345-353, 2016. 